\title{
TIME BUDGET PRESSURE, KOMPLEKSITAS AUDIT DAN KUALITAS AUDIT
}

\author{
Ismail ', Andi Arman', Abd Salam ${ }^{3}$, Linda Arisanti Razak ${ }^{4}$ \\ 1) Universitas Muhammadiyah Makassar
}

\begin{abstract}
The purpose of this study is to examine the effect of time budget pressure and audit complexity on audit quality. The population and sample of this study used all auditors KAP in Makassar City. Determination of the sample was selected by purposive sampling method with the criteria of respondents not limited by the position of auditors in KAP (partners, managers, seniors and auditor staff) so that all auditors who work in KAP can be respondents. Hypothesis testing uses multiple linear regression analysis. The analysis shows that time budget pressure has a negative effect on audit quality. However, audit complexity does not affect audit quality. This illustrates that if the auditor has time pressure in carrying out his work will have an impact on the decline in audit quality, but the complexity of the auditor's work if it does not have time pressure in carrying out the audit does not have an impact on the decline in audit quality.
\end{abstract}

Keywords : : Audit Complexity; Audit Quality; Time Budget Pressure

Correspondence to : ismail.badollahi@unismuh.ac.id

\begin{abstract}
ABSTRAK
Penelitian ini bertujuan untuk menguji pengaruh time budget pressure dan kompleksitas audit terhadap kualitas audit. Populasi dalam penelitian ini adalah semua auditor di Kantor Akuntan Publik di Kota Makassar. Sampel dipilih dengan metode purposive sampling dengan kriteria responden tidak dibatasi oleh posisi auditor dalam KAP (mitra, manajer, senior dan staf auditor) sehingga semua auditor yang bekerja di KAP dapat dimasukkan sebagai responden. Hipotesis diuji dengan teknik analisis data yang digunakan dalam penelitian ini adalah analisis regresi linier berganda. Hasil analisis menunjukkan bahwa time budget pressure berpengaruh negative terhadap kualiatas audit. Namun, kompleksitas audit tidak berpengaruh terhadap kualitas audit. Hal ini menggambarkan bahwa jika auditor mempunyai tekanan waktu dalam melaksanakan pekerjaannya akan berdampak terhadap penurunan kualitas audit, akan tetapi kompleksnya pekerjaan auditor jika tidak mempunyai tekanan waktu dalam melaksanakan audit tidak berdampak terhadap penurunan kualitas audit.
\end{abstract}

Kata Kunci : Time Budget Pressure; Kompleksitas Audit; Kualitas Audit

Korespondensi : ismail.badollahi@unismuh.ac.id 


\section{BALANCE : Economic, Business, Management, and Accounting J ournal Vol. XVII No. 2 |Bulan J uli Tahun 2020}

\section{PENDAHULUAN}

Para pemengang saham dan manajemen menunjuk sebuah Kantor Akuntan Publik atau disingkat KAP terkait dengan perbedaan informasi yang diperoleh. Pada prinsipnya investor membutuhkan informasi yang akurat, dan menghindari terjadinya informasi yang berbeda yang berpotensi dapat merugikan. Maka, diperlukan KAP yang independen agar tidak terjadi perbedaan informasi antara manajemen dan investor.

Menurut Kesuma dan Dwirandra (2019), bahwa agar bisa meyakinkan investor dan pihak lainnya maka dibutuhkan pihak yang memiliki komptensi dan independent dalam memberikan jasa audit dari KAP. Jasa audit yang diberikan tentunya memiliki kualitas audit yang baik. Menurut Pratiwi dan Dwirandra (2018) bahwa saat ini kualitas audit harus dipertanyakan di mana terdapat berbagai kasus praktik tidak sehat terkait akuntansi untuk perusahaan yang telah diaudit oleh akuntan publik dan bahkan mendapatkan opini wajar tanpa pengecualian. Kondisi ini tentu saja memberikan risiko besar bagi profesi akuntan publik yang keberadaannya ditentukan oleh pendapat yang diberikan pada laporan keuangan yang diaudit.

Kuliatas audit merupakan hal yang sangat kompleksitas, karena mengandung banyak faktor yang memperngaruhi kualitas audit. Hal tersebut menyebabkan kualitas audit sangat sulit diukur. Namun, secara teori kualitas pekerjaan auditor biasanya dihubungkan dengan kualifikasi keahlian, ketepatan waktu penyeselesaian pekerjaan, kecukupan bukti pemeriksaan yang kompoten pada biaya yang paling rendah serta sikap independensinya dengan klien.

Salah satu faktor yang mempengaruhi kualitas auditor adalah time budget pressure. Time budget pressure menyebabkan stress individual yang muncul akibat tidak seimbangnya tugas dan waktu yang tersedia serta mempengaruhi etika professional melalui sikap, nilai, perhatian, dan perilaku auditor (Sososutikno dan Christiani, 2003). Time budget dilakukan agar proses pemeriksaan yang telah dilakukan sesuai dengan cost-benefitnya. Auditor yang membutuhkan waktu yang lebih lama dari waktu normal untuk sebuah tugas bukan merupakan hal yang baik dimata atasan dan tidak membawa pengaruh yang baik pula bagi peningkatan karirnya. Adanya time budget yang ketat menimbulkan tekanan (pressure) terhadap auditor yang menuntutnya menghasilkan laporan audit yang berkualitas dengan waktu yang telah dianggarkan, hal ini merupakan tantangan tersendiri bagi auditor.

Dampak penurunan kualitas audit dapat menurunkan kepercayaan publik terhadap profesi akuntan utamanya pada auditor dalam melakukan pemeriksaan audit yang pada akhirnya berakibat pada profesi itu sendiri. Audit yang berkualitas akan mampu mengurangi faktor ketidakpastian yang berkaitan dengan laporan keuangan yang disajikan oleh pihak manajemen dan perbaikan terus menerus atas kualitas audit harus terus dilakuakan (Tandiontong, 2016). Dengan demikian wajar jika kemudian kualitas audit menjadi topik yang selalu memperoleh perhatian yang mendalam dari profesi akuntan khususnya bagi auditor, pemerintah, masyarakat dan investor.

Beberapa penelitian sebelumnya telah menguji pengaruh time budget pressure terhadap kualitas audit dan menunjukkan hasil yang tidak konsisten. Studi yang dilakukan oleh Arisinta (2013) bahwa semakin tinggi time budget pressure, maka semakin tinggi kecenderungan auditor untuk melakukan perilaku audit disfungsional sehingga menurunkan kualitas audit. Hasil ini sejalan dengan penelitian Ningsih (2013); Kurnia (2014); Nurhayati (2017) dan Nurhasanah dkk (2018). Studi tersebut 


\section{BALANCE : Economic, Business, Management, and Accounting J ournal}

Vol. XVII No. 2 |Bulan J uli Tahun 2020

menyatakan bahwa semakin tinggi time budget pressure yang dirasakan oleh auditor dapat menyebabkan rendahnya kualitas audit yang dihasilkan. Penelitian ini bertentangan dengan penelitian yang dilakukan oleh Arisinta (2013); Jelista (2015); Atiqoh (2016) yang menyatakan bahwa time budget pressure berpengaruh positif terhadap kualitas audit. Studi ini menyatakan bahwa semakin tinggi time budget pressure yang diberikan dirasakan oleh auditor, semakin tinggi kualitas audit.

\section{H1: Time budget pressure berpengaruh terhadap kualitas audit}

Selain time budget pressure, variabel kompleksitas audit juga dianggap berpengaruh terhadap kualitas audit. Kompleksitas audit didasarkan pada persepsi individu tentang kesulitan suatu tugas audit, sulit bagi seseorang namun mudah bagi orang lain (Prasita dan Priyo, 2007). Kompleksitas audit juga bersifat paling penting karena kecenderungan bahwa tugas melakukan audit adalah tugas yang banyak menghadapi persoalan kompleks.

Menurut Ratha dan Ramantha (2015) Kompleksitas audit membuat soeorang auditor berperilaku disfungsional, dimana saat semakin banyak dan sulitnya tugas yang dia dapat membuat dirinya melewatkan beberapa tugas atau mengerjakan tugas tersebut secara tidak maksimal sehingga kinerjanya menjadi menurun

\section{H2: Kompleksitas audit berpengaruh terhadap kualitas audit}

\section{METODE PENELITIAN}

Penelitian ini bertujuan untuk menguji pengaruh time budget pressure dan kompleksitas audit terhadap kualitas audit. Populasi dalam penelitian ini adalah semua auditor di Kantor Akuntan Publik di Kota
Makassar. Sampel dipilih dengan metode purposive sampling dengan kriteria responden tidak dibatasi oleh posisi auditor dalam KAP (mitra, manajer, senior dan staf auditor) sehingga semua auditor yang bekerja di KAP dapat dimasukkan sebagai responden. Hipotesis diuji dengan teknik analisis data yang digunakan dalam penelitian ini adalah analisis regresi linier berganda

\section{HASIL PENELITIAN}

Model analisis regresi yang digunakan dalam penelitian ini adalah Analisis Regresi Berganda dengan bantuan program IBM SPSS versi 22. Hasil tes ditunjukkan pada Tabel 1 berikut ini

TABEL 1. Hasil Pengujian Hipotesis

\begin{tabular}{lcl}
\hline Nama & Hasil & Keterangan \\
\hline $\begin{array}{l}\text { Time Budget } \\
\text { Pressure }\end{array}$ & $0.062^{*}$ & Sig - \\
\hline $\begin{array}{l}\text { Kompleksitas } \\
\text { Audit }\end{array}$ & 0.178 & Tidak Sig \\
\hline
\end{tabular}

\section{PEMBAHASAN}

Hasil pengujian hipotesis menunjukkan bukti bahwa time budget pressure memiliki pengaruh negatif dan signifikan terhadap kualitas audit. Hasil ini berarti bahwa semakin tinggi time budget pressure yang dirasakan oleh auditor, semakin rendah kualitas audit yang dihasilkan dan semakin rendah time budget pressure yang dirasakan oleh auditor, semakin tinggi pula kualitas audit yang dihasilkan. Hasil pengujian hipotesis ini mendukung hasil penelitian oleh Haribowo dan Marzuki (2014); Pramudianti dan Setiawan (2016) dan Devi dkk (2017) yang menunjukkan efek negatif time budget pressure terhadap kualitas audit. Hasil penelitian ini mendukung teori atribusi dimana time budget pressure menyabkan auditor mempunyai tekanan dalam melaksanakan pekerjaannya yang kemudian akan mempengaruhi sikap, niat, dan perilaku dalam pelaksanaan program 


\section{BALANCE : Economic, Business, Management, and Accounting J ournal}

Vol. XVII No. 2 |Bulan J uli Tahun 2020

audit. Dan berdasarkan itu, kualitas audit yang dihasilkan rendah.

Hasil pengujian hipotesis kedua menunjukkan bahwa kompleksitas audit tidak memiliki pengaruh terhadap kualitas audit. Hasil penelitian membuktikan bahwa sekalipun kompleksitas audit seringkali dihadapi auditor dalam pelaksanaan tugasnya, tetapi adanya pemahaman auditor terhadap prosedur audit dan sistem informasi dapat membantu auditor dalam melakukan pemeriksaan. Pemahaman auditor memberikan kemudahan untuk memahami bagaimana resiko internal dan eksternal yang mempengaruhi audit serta kemudahan dalam menentukan prosedur audit yang akan dipilih, sehingga kompleksitas audit tidak memperngaruhi penurunan kuliatas auditnya.

\section{KESIMPULAN}

Tujuan penelitian ini adalah menguji pengaruh time budget pressure dan kompleksitas audit terhadap kulaitas audit. Hasil analisis menunjukkan bahwa time budget pressure berpengaruh negative terhadap kualiatas audit. Namun, kompleksitas audit tidak berpengaruh terhadap kualitas audit. Hal ini menggambarkan bahwa jika auditor mempunyai tekanan waktu dalam melaksanakan pekerjaannya akan berdampak terhadap penurunan kualitas audit, akan tetapi kompleksnya pekerjaan auditor jika tidak mempunyai tekanan waktu dalam melaksanakan audit tidak berdampak terhadap penurunan kualitas audit

\section{DAFTAR PUSTAKA}

Anugrah, I. S., Kamaliah, K., \& Ilham, E. (2017). Pengaruh Time Budget Pressure, Kompetensi dan Independensi Terhadap Kualitas Audit Dengan Etika Profesi Sebagai Variable Moderasi (Doctoral dissertation, Riau University).

Arisinta, Octaviana. 2013. Pengruh Kompetensi, Independensi, Time Budget Pressuredan Audit Fee
Terhadap Kualitas Audit Pada Kantor Akuntan Publik di Surabaya. Jurnal. Fakultas Ekonomi dan Bisnis Universitas Airlangga.

Atiqoh, N., \& Riduwan, A. (2016). Pengaruh Due Professional Care, Motivasi Auditor, Time Budget Pressure terhadap Kualitas Audit. Jurnal Ilmu dan Riset Akuntansi (JIRA), 5(2).

Devi, Arista and Wayan Ramantha. 2017. "Tekanan Anggaran Waktu, Locus of Control , Sifat Machiavellian, Pelatihan Auditor Sebagai Anteseden Perilaku Disfungsional Auditor.” Akuntansi Universitas Udayana 18:2318-45.

Jelista, M. (2015). Pengaruh Kompleksitas Audit. Tekanan Anggaran Waktu, Dan Pengalaman Auditor Terhadap Kualitas Audit, 2(2), 1-15.

Kurnia, W., Khomsiyah, K., \& Sofie, S. (2014). Pengaruh Kompetensi, Independensi, Tekanan Waktu, dan Etika Auditor terhadap Kualitas Audit. Jurnal Akuntansi Trisakti, 1(2), 49-67.

Ningsih, A. P. R. C. (2013). Pengaruh Kompetensi, Independensi, dan Time Budget Pressure Terhadap Kualitas Audit. E-Jurnal Akuntansi, 92-109.

Nurhasanah, D., Hasan, A., \& Savitri, E. (2018). PENGARUH TIME BUDGET PRESSURE, KOMPETENSI, INDEPENDENSI, DAN INTEGRITAS TERHADAP KUALIAS AUDIT DENGAN KECERDASAN EMOSIONAL SEBAGAI VARIABEL MODERASI (STUDI EMPIRIS PADA KANTOR AKUNTAN PUBLIK KOTA PEKANBARU DAN PADANG). Jurnal Akuntansi (Media Riset Akuntansi \& Keuangan), 6(2), 174-189.

Nurhayati, E. (2017). Pengaruh Pengalaman, Independensi, dan Time Budget Pressure Terhadap Kualitas Audit Dengan Etika Sebagai Variabel Pemoderasi (Studi Empiris pada Auditor di KAP Bandung). Jurnal Riset Keuangan Dan Akuntansi, 1(02).

Pratiwi, M. C. A., \& Dwirandra, A. N. B. (2018). Tekanan Waktu Memoderasi Pengaruh Independensi Auditor dan Komitmen Organisasi pada Kinerja Auditor KAP di Provinsi Bali. E-Jurnal Akuntansi, 1038-1065.

Pramudianti, Astri \& Setiawan, Ngadirin. (2016). Pengaruh Tekanan Anggaran Waktu, Prosedur Review, Kontrol Kualitas dan Karakteristik Personal Auditor Terhadap Perilaku Pengurangan Kualitas Audit (Studi Empiris Pada Kantor Akuntan Publik Di Yogyakarta dan Solo). Jurnal Nominal, 5(2), 29-41.

Prasita, A. \& Priyo, A. (2007). Pengaruh Kompleksitas Audit dan Tekanan Anggaran dan Waktu Terhadap Kualitas Audit dengan Moderasi Pemahaman Terhadap Sistem Informasi. Fakultas Ekonomi, Universitas Kristen Satya Wacana. 
BALANCE : Economic, Business, Management, and Accounting J ournal Vol. XVII No. 2 |Bulan J uli Tahun 2020

Ratha, I. D., \& Ramantha, I. W. (2015). Pengaruh Due Profesionalcare Akuntabilitas, Kompleksitas Audit dan Time Budget Pressure Terhadap Kualitas Audit. Jurnal Akuntansi.

Sososutikno, \& Christiani. (2003). Hubungan Tekanan Anggaran Waktu dengan Perilaku Disfungsional serta Pengaruhnya terhadap Kualitas Audit . Surabaya: Simposium Nasional Akuntansi.

Tandiontong, M. 2016. Kualitas Audit dan Pengukurannya. Cetakan ke. Bandung: Alfabeta. 